\title{
Determinants of contraceptive methods use after voluntary induced abortion at the Yaounde Central Hospital, Cameroon
}

\author{
Florent Y. Fouelifack ${ }^{1,2 *}$, Cadette C. N. Mba ${ }^{2}$, Anyimbi M. Ofeh ${ }^{2}$, Pierre M. Tebeu
}

\begin{abstract}
${ }^{1}$ Department of Obstetrics and Gynecology, Yaounde Central Hospital, Yaounde, Cameroon
${ }^{2}$ Department of Surgery and Specialties, Higher Institute of Medical Technologies of Nkolondom, Yaounde, Cameroon

${ }^{3}$ Inter-State Center for Higher Education in Public Health of Central Africa (CIESPAC), Brazzaville, Congo
\end{abstract}

Received: 07 June 2021

Accepted: 05 July 2021

\section{*Correspondence:}

Dr. Florent Y. Fouelifack,

E-mail: yfouelifack@gmail.com

Copyright: () the author(s), publisher and licensee Medip Academy. This is an open-access article distributed under the terms of the Creative Commons Attribution Non-Commercial License, which permits unrestricted non-commercial use, distribution, and reproduction in any medium, provided the original work is properly cited.

\begin{abstract}
Background: Abortion is the termination of pregnancy with expulsion of the product of conception before the age of fetal viability- 28 weeks. In Africa, 96\% of abortions are unsafe and there is an estimated 1 death for 150 abortions. Few data are available in Cameroon on the determinants of contraception after a voluntary termination of pregnancy. The objective of this study to investigate the determinants of the use of contraceptive methods after a voluntary termination of pregnancy.

Methods: The study was descriptive cross-sectional lasting 09 months in the gynecology and obstetrics unit of the Yaounde Central Hospital. We included women admitted to this unit who have already had at least one abortion. All women who did not give their consent were excluded. The data were entered and analyzed using the Epi-info software version 7.2.2.6. The tools used to express our results were the Student's and Whitney's test, the Wald test and the Odd ratios (OR) with their $95 \%$ confidence interval. The significance level was $5 \%$.

Results: Out of 139 participants, $86(61.87 \%)$ had already used a modern contraceptive method after voluntary termination of pregnancy. The mean age was $27.13 \pm 6.16$ years with extremes of 16 and 42 years. Being single and having unwanted pregnancies independently increased contraceptive method use after abortions.

Conclusions: An intensification of campaigns for behaviour change and men's involvement would further improve the use of contraceptive methods after abortion.
\end{abstract}

Keywords: Determinants induced, Contraceptive methods, Contraceptive, Voluntary induced abortion, Yaounde

\section{INTRODUCTION}

Abortion is defined as the accidental, voluntary, medical or therapeutic termination of pregnancy before the legal term of viability, the date from which the viable child born alive is expected to be able to develop and live to an advanced age. However, this term of fetal viability varies from country to country depending on the resources and the technical platform. According to the WHO and in developed countries It is 22 weeks of pregnancy. ${ }^{1-3}$ Traditionally, it is 180 days or 28 weeks in developing countries. ${ }^{2,4}$ Contraception is the set of methods used to prevent the occurrence of an unwanted pregnancy. ${ }^{5}$ It is a necessity to plan pregnancy and to try to reduce the number of voluntary terminations of pregnancies (abortions). The International Conference on population and development, held in Cairo in 1994, recognized the need to put in place quality reproductive health services, regardless of the country's official position on the legality of an abortion. ${ }^{6}$

Recent estimates give a total figure of around 30 million induced abortions annually worldwide. About 19-20 million of these abortions are done in unsafe conditions 
resulting in a significant number of maternal deaths and serious sequelae such as infertility. ${ }^{7}$ Many women who have had an abortion are again at risk of being involved in a cycle of unwanted pregnancies and induced abortions (elective abortion). It was in order to break this vicious cycle of unsafe abortions that post-abortion family planning was introduced into post-abortion care. ${ }^{8}$ Family planning (FP) is a set of technical and educational measures that allow couples to decide the number of children and the time of their birth, while allowing the pursuit of harmonious sexual activity. ${ }^{9}$ Different means are used in family planning. These are more or less old and more or less effective contraceptive methods. ${ }^{9}$ Postabortion contraception is part of the post-abortion care package and helps improve women's sexual and reproductive life and health. ${ }^{10,11}$

In Africa, $96 \%$ of abortions are unsafe and an estimated 3,740,000 clandestine induced abortions performed each year, with an estimated mortality ratio of 1 death per 150 abortions. Most women who have a clandestine induced abortion have an obvious motivation- that of having contracted an unwanted pregnancy. This is why the access of these women to a wide choice of modern contraceptive methods must be facilitated to enable them to control their fertility in complete safety. ${ }^{10}$ Contraception is a set of measures that make sexual intercourse non-fertile, temporarily and reversibly. ${ }^{12}$ Research on factors associated with the use of contraceptive methods would encourage the use of FP, thereby reducing the incidence of unsafe abortions and their complications.

The general objective of this study was to investigate the determinants of the use of contraceptive methods after a voluntary termination of pregnancy, in particular to determine the proportion of women using contraceptives after a voluntary termination of pregnancy, to describe the socio-demographic, gynecological and obstetrical characteristics of women using contraceptives after an abortion, and to identify factors associated with the use of contraceptive methods after an abortion.

\section{METHODS}

We conducted a descriptive cross-sectional study with prospective and retrospective data collection, over a period of 09 months, i.e.; from 11 January 2018 to 07 January 2019 in the gynecology and obstetrics unit of the Central Hospital of Yaounde (HCY). This unit was a reference center that receives most of the gynecological and obstetrical emergencies in the city of Yaounde, and even in the Center region. About 350 deliveries are performed there per month.

\section{Sampling}

Our sampling was consecutive and exhaustive. The study population consisted of all women admitted to the HCY maternity hospital for abortion. All women who have had an abortion at least once were included. All women who did not consent to the study were excluded.

\section{Procedure}

From the consultation register, all women who had already had an abortion were identified. Those who had already had an abortion and hospitalized for complications or for any reason whatsoever were sought and identified in the postpartum department. The patients were approached to explain the purpose and the possible advantages of our study. Recruitment was done consecutively. After verbal or written consent from any participants, the interview began, and the files were consulted to complete the information. All the information was reported on preestablished and tested questionnaires.

The independent variables were whether or not a contraceptive method was used after abortion. The dependent variables were socio-demographic (age, marital status, level of education, profession, religion), gynecoobstetric (pregnancy (number of pregnancies), parity (number of births after 28 weeks)), the abortion method used, age of the last terminated pregnancy, the number of abortions, the reasons for the abortion, the qualification of the practitioner, the medical history, the type of contraception, the reason for not using contraceptive methods, the reasons for choosing the method, the contraceptive complications and contraceptive adherence.

\section{Statistical analysis}

The data collected and reported on the questionnaires were recorded on the computer and analyzed using EPI INFO 7.2.2.6 software. Microsoft word and excel 2013 software were used for the production of tables and graphs. We used an $\alpha$ error threshold of $5 \%$. The mean values were expressed with their 95\% confidence interval. Quantitative data was defined by their mean and standard deviation when the distribution was considered normal. Otherwise, they were described by their median. Qualitative variables were described in terms of proportion. The tools used to find the determinants were the odd ratio (OR) calculated with a $95 \%$ confidence interval. Single and multiple logistic regressions were used to relate dependent variables to independent variables.

\section{RESULTS}

\section{Generalities}

Of 200 women approached in the postpartum ward during the study period, 145 gave their consent. Among the latter, 6 having incorrectly completed the technical sheet were excluded from the analysis. We thus retained and analyzed the files of 139 participants. The mean age of the participants was $27.13 \pm 6.16$ years with the extremes of 16 and 42 years. Of the 139 participants, $86(61.87 \%)$ used contraception after an abortion and $53(38.13 \%)$ did not use it, i.e.; a frequency of use of a contraceptive method after abortion of $61.87 \%$. The participants were then 
divided into two groups according to whether they had used $(\mathrm{N}=86)$ or not $(\mathrm{N}=53)$ a contraceptive method after the abortion. The rest of the analyzes are carried out by comparing the two groups.

\section{Socio-demographic determinants}

Apart from the 'single' marital status which appeared to increase the use of contraceptive methods after abortion, all the other socio-demographic variables had a homogeneous distribution (Table 1).

\section{Gynecological and obstetrical determinants}

Only the variable 'reason for abortion' was distributed heterogeneously. Women with unwanted pregnancies used more contraceptive methods after abortion. All other variables were evenly distributed (Table 2).

\section{Independent determinants of the use of contraceptive methods after abortion}

To find the independent determinants of the use of contraceptive methods after abortion, a logistic regression was done in Table 3 using the variables whose distribution was heterogeneous during the simple regressions.

Being single and having unwanted pregnancies independently increased contraceptive use after abortions (Table 3).

Table 1: Socio-demographic determinants of the use of contraception after abortion.

\begin{tabular}{|c|c|c|c|c|c|c|c|c|}
\hline \multirow{3}{*}{ Variables } & \multicolumn{6}{|c|}{ Use of contraceptive method after induced abortion } & \multirow{3}{*}{ OR $(95 \% \mathrm{CI})$} & \multirow{3}{*}{$P$ value } \\
\hline & \multicolumn{2}{|c|}{ Total } & \multicolumn{2}{|c|}{ Yes } & \multicolumn{2}{|c|}{ No } & & \\
\hline & $\mathbf{N}=\mathbf{1 3 9}$ & $\%$ & $\mathbf{N}=86$ & $\%$ & $\mathbf{N}=53$ & $\%$ & & \\
\hline Age group (years) & & & & & & & & 0.87 \\
\hline $16-25$ & 58 & 41.73 & 34 & 39.53 & 24 & 45.28 & $0.7(0.19-2.62)$ & 0.60 \\
\hline $26-35$ & 69 & 49.64 & 44 & 51.16 & 25 & 47.17 & $0.8(0.2-3.2)$ & 0.84 \\
\hline $36-42$ & 12 & 8.63 & 8 & 9.30 & 4 & 7.55 & & \\
\hline \multicolumn{9}{|l|}{ Marital status } \\
\hline Married & 38 & 26.62 & 18 & 47.37 & 20 & 52.63 & 1 & \\
\hline Single & 102 & 73.38 & 68 & 67.33 & 33 & 32.67 & $2.28(1.07-4.89)$ & 0.03 \\
\hline Level of education & & & & & & & & 0.17 \\
\hline Primary & 32 & 23.02 & 16 & 30.19 & 16 & 18.60 & $0.38(0.15-0.98)$ & 0.04 \\
\hline Secondary & 57 & 41.01 & 34 & 39.53 & 23 & 43.40 & $0.57(0.25-1.29)$ & 0.18 \\
\hline Higher education & 50 & 35.97 & 36 & 41.86 & 14 & 26.42 & & \\
\hline Profession & & & & & & & & 0.62 \\
\hline Student & 46 & 33.09 & 33 & 38.37 & 13 & 24.53 & $1.81(0.72-4.56)$ & 0.3 \\
\hline Housewife & 32 & 23.02 & 19 & 22.09 & 13 & 24.53 & $1.04(0.39-2.7)$ & 0.2 \\
\hline Employed & 25 & 17.99 & 13 & 15.12 & 12 & 22.64 & $0.77(0.27-2.16)$ & 0.9 \\
\hline Trader & 36 & 25.90 & 21 & 24.42 & 15 & 28.30 & & 0.6 \\
\hline Religion & & & & & & & & 0.1 \\
\hline Christian & 120 & 86.33 & 75 & 87.21 & 45 & 84.91 & $0.41(0.08-2.04)$ & 0.28 \\
\hline Muslim & 9 & 6.47 & 3 & 3.49 & 6 & 11.32 & $0.12(0.02-1)$ & 0.05 \\
\hline Others & 10 & 7.19 & 8 & 9.30 & 2 & 3.77 & & \\
\hline
\end{tabular}

Table 2: Gynecological and obstetrical determinants of the use of contraception after abortion.

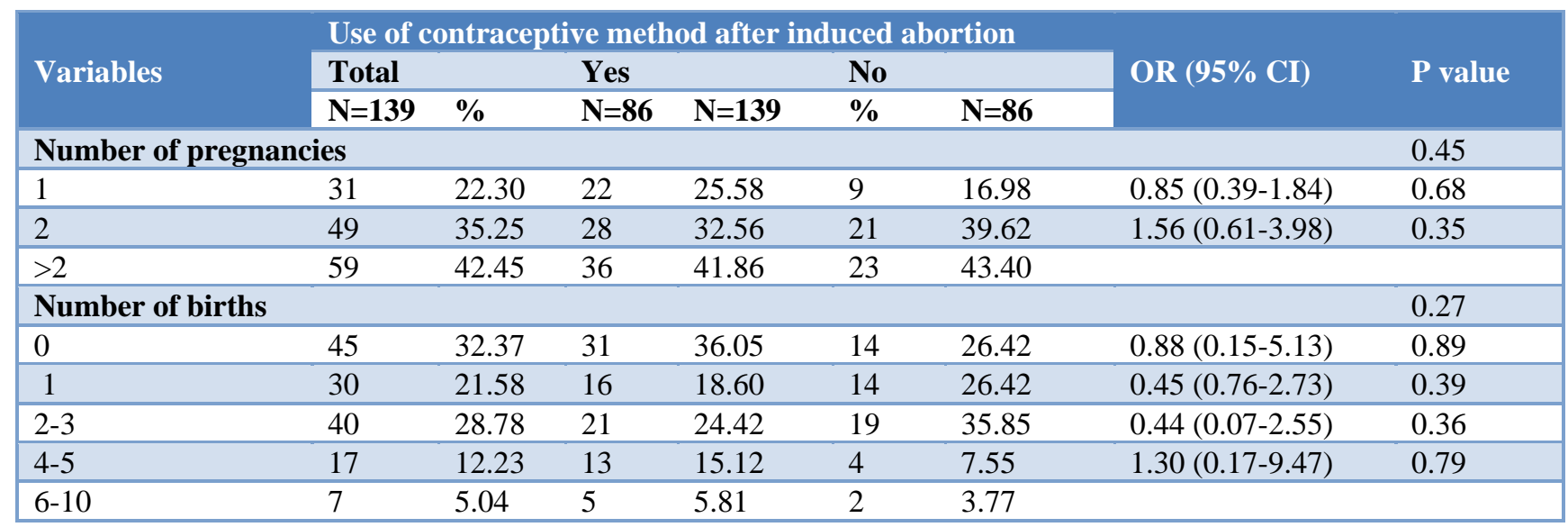




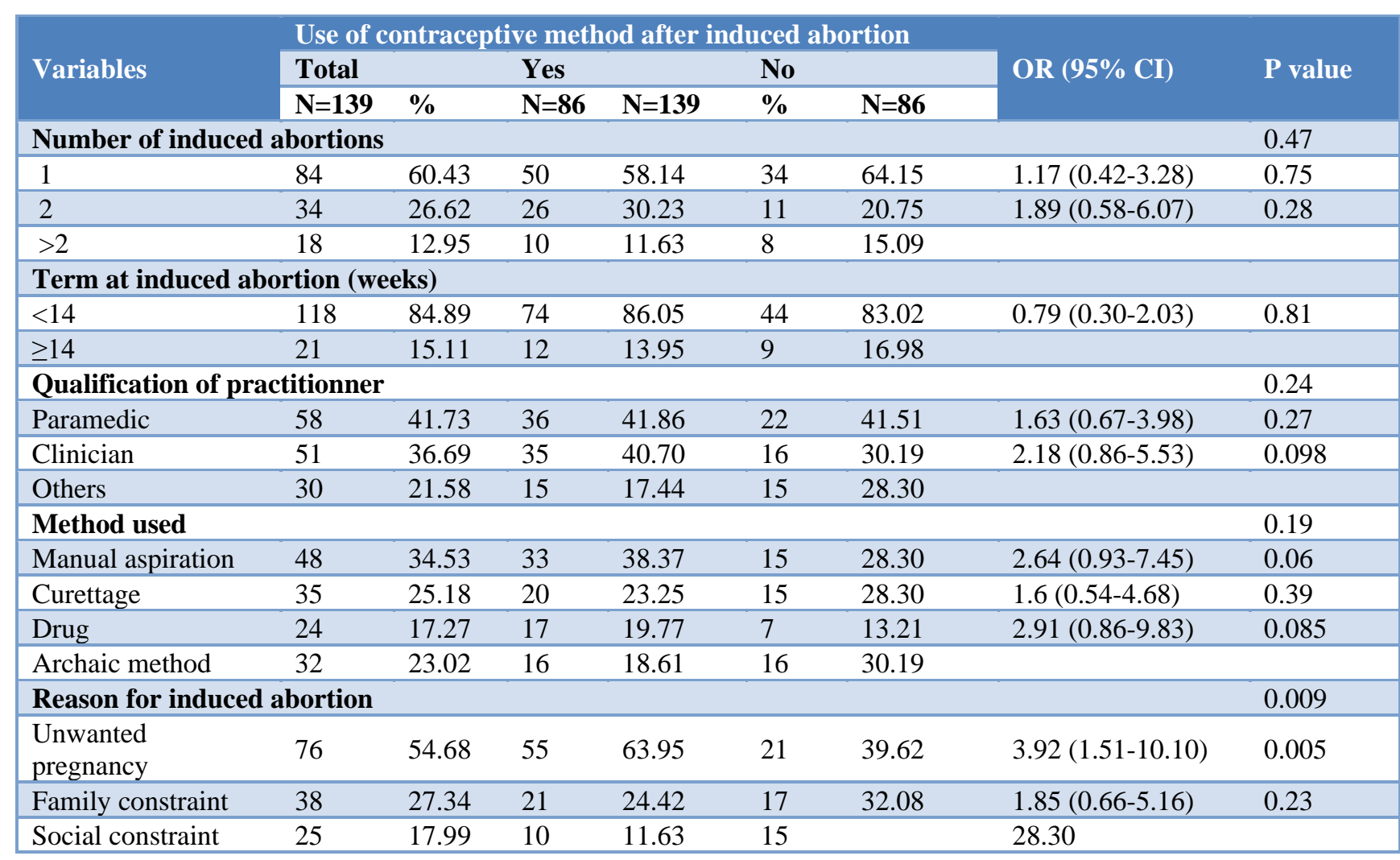

Table 3: Independent determinants of the use of contraceptive methods after abortion.

\begin{tabular}{|c|c|c|c|c|c|c|c|c|}
\hline \multirow{3}{*}{ Variables } & \multicolumn{4}{|c|}{$\begin{array}{l}\text { Use of contraceptive after } \\
\text { induced abortion }\end{array}$} & \multirow{3}{*}{ OR $(95 \% \mathrm{CI})$} & \multirow{3}{*}{ P value } & \multirow{3}{*}{$\operatorname{aOR}(95 \% \mathrm{CI})$} & \multirow{3}{*}{$P$ value } \\
\hline & \multicolumn{2}{|c|}{ Yes } & \multicolumn{2}{|c|}{ No } & & & & \\
\hline & $N=86$ & $\%$ & $\mathrm{~N}=53$ & $\%$ & & & & \\
\hline \multicolumn{9}{|l|}{ Marital status } \\
\hline Married & 18 & 47.37 & 20 & 52.63 & 1 & & & \\
\hline Single & 68 & 67.33 & 33 & 32.67 & $2.28(1.07-4.89)$ & 0.03 & $2.53(1.52-4.22)$ & 0.02 \\
\hline \multicolumn{9}{|c|}{ Reason for induced abortion } \\
\hline Unwanted pregnancy & 55 & 72.37 & 21 & 27.63 & $3.92(1.52-10.01)$ & 0.003 & $2.82(1.51-5.09)$ & 0.03 \\
\hline Family constraints & 21 & 55.26 & 17 & 44.74 & $1.85(0.66-5.16)$ & 0.23 & & \\
\hline Social constraints & 10 & 40 & 15 & 60 & & & & \\
\hline
\end{tabular}

\section{DISCUSSION}

\section{General}

The mean age of $27.13 \pm 6.16$ years found in our study is close to those of Rose in New Zealand and of Prata et al in Ethiopia who respectively reported mean ages of 24.7 years and 25 years old. ${ }^{13,14}$

In our study, $61.87 \%$ of patients had used a post-abortion contraceptive method. These results are similar to those of Moreau in France, Ceylan et al in Turkey, Prata et al in Ethiopia, Kavanaugh et al in the United States who found respectively $77 \%, 80.1 \%, 86 \%, 67 \%$ post-abortion contraceptive use rate. ${ }^{14}$ Abortion induces some changes in the prevention of unwanted pregnancies, although twothirds of women have not received any post-abortion counseling. ${ }^{15}$
In Mali, $45 \%$ of women use a method after an abortion, twice as many as before their abortion ( $23 \%$ of users). ${ }^{16}$ In Togo, the proportion of contraceptive users increases from $20 \%$ before the abortion to $51 \%$ after. ${ }^{17}$ In Cote Ivoire, the contraceptive prevalence before and after abortion increases overall, going from 25 to $31 \%$ for natural methods and from 14 to $34 \%$ for modern methods.

\section{Determinants of the use of contraceptive methods after abortion}

The socio-demographic variable marital status 'single' (Table 1) and the gyneco-obstetric variable reason for abortion 'unwanted pregnancy' (Table 2) increased the use of contraceptive methods after abortion. All the other socio-demographic and obstetrical gynecological variables had no influence of contraceptive use. These data were different from those of David et al, which showed an 
association between socio-cultural factors, gender, religion and local customs. ${ }^{18}$ This difference could be explained by the fact that their sample consisted of women in Nigeria who had had an abortion or not, while our study concerned only women who had already experienced an abortion. Olaitan found no association between contraceptive use and women's socioeconomic status, religion and cultural values. In addition, her study shows that the level of education of partners and their participation in the choice of contraceptive methods influenced the choice of contraceptives in couples. ${ }^{19}$ The different types of contraception were not determined in our study. Post-abortion care (PAC) consultations do not directly involve spouses in our setting, whereas postabortion family planning should begin immediately withspousal counselling at this important stage. ${ }^{6}$

After logistic regression (Table 3), the two variables remain independently associated with the use of contraception. The choice of post-abortion contraceptive methods does not really depend on the history and the management. Some authors have found the role of the partner in the decision to use post-abortion contraception. ${ }^{11,18,19}$ However, this factor was not taken into account in our study.

\section{Limitations}

The subject of abortion is difficult to tackle in our Cameroonian context where the law on abortions remains very restrictive. This could lead to falsehoods. Also, the data collection being retrospective, we could have recall bias.

\section{CONCLUSION}

At the end of this study, $61.87 \%$ of participants used a contraceptive method after abortion. Being single and having unwanted pregnancies independently increased contraceptive use after abortions. An intensification of provider behavior changes communication and men's involvement would further improve the use of contraceptive methods after abortion.

\section{Funding: No funding sources}

Conflict of interest: None declared

Ethical approval: The study was approved by the Institutional Ethics Committee

\section{REFERENCES}

1. WHO. Safe Abortion: Technical and Policy Guidance for Health Systems. Geneva: World Health Organization; 2004. Available at: www.who.intlreproductive-health. Accessed on 28 May 2021.

2. WHO Scientific Group on Spontaneous and Induced Abortion \& World Health Organization. Spontaneous and induced abortion: report of a WHO Scientific Group, 1970. Available at: https://apps.who.int/iris/handle/ 106638211. Accessed on 28 May 2021.

3. Sournia JC, Milliez J, Bernard P, Body G, Boog G, Charles J, et al. Dictionary of Obstetrics Gynecology. 11th ed. Paris: International Council of the French Language; 1999.

4. Delamere. Delamere Illustrated Dictionary of Medical Terms. 5th ed. Malouir; 2003.

5. Campana A. Family planning. Switzerland, 2008. Available at: http://www.gfmer.ch/Cours/Planification familiale.html. Accessed on 28 May 2021.

6. Huntington D. Operational research in postabortion care: Progress and challenges. Report of a global meeting. Global renions in operational research on post-abortion care. New York, NY: Population council; 1998: 19-21.

7. WHO. Safe Abortion: Technical and Policy Guidance for Health Systems. Geneva: World Health Organization; 2004. Available at: www.who.intlreproductive-health. Accessed on 28 May 2021.

8. Curtis C, Huber D, Moss KT. Postabortion family planning: addressing the cycle of repeat unintended pregnancy and abortion. Int Perspect Sex Reprod Health. 2010;36(1):44-8.

9. Gendreau, F. The demography of African countries: synthesis review. Population. 1977;4:899-943.

10. Diallo SYK. Family planning in Guinea: experience of the Guinean association for family well-being (AGBEF) in Conakry, from 2003 to 2007 Guinea. University of Conakry; 2009.

11. Meyer L. Family planning: objectives, means, regulations, structures. The practitioner's review. 1991;41(17):1615-7.

12. Ministry of Social Action and National Solidarity. Lexicon of the usual concepts of the social action sector. Burkina Faso: National Institute of Statistics and Demography; 2008.

13. Sally B. Rose, Lawton BA, Brown AS. Uptake and adherence to long-acting reversible post-abortion contraception. Elsevier. 2010;82(4):34553.

14. Prata N, Bell S, Holston M, Gerdts C, Melkamu Y. Factors associated with choice of postabortion contraception in Addis Ababa, Ethiopia. African $\mathbf{J}$ Reprod Health. 2011;15(3):51-7.

15. Guillaume A. The Role of Abortion in the Fertility Transition in Abidjan (Côte d'Ivoire) during the 1990s Population. Cairn Info. 2003;6(58):657-86.

16. Konate MK, Sissoko F, Gueye M, Trarore B, Diabate TF. The social consequences of induced abortion in Bamako, 1999. Available at: http://portails.cilss.bf:85documents/ 1317. Accessed on 28 May 2021.

17. Bouke A, Calves A, Lardoux S, Springer L. Induced Abortion in Lomé, Togo: Trends and Role in Fertility Decline. Population. 2012;67(2):309-36.

18. David O. Socio-Cultural and Norms Factors Influencing Family Planning Choices Among Couples in Ibadan Metropolis, Nigeria. European J Scientif Res. 2008;3(2):212-8.

19. Olaitan OL. Factors influencing the choice of family planning among couples in Southwest Nigeria. Int J Med Sci. 2011;3(7):227-32.

Cite this article as: Fouelifack FY, Mba CCN, Ofeh AM, Tebeu PM. Determinants of contraceptive methods use after voluntary induced abortion at the Yaounde Central Hospital, Cameroon. Int J Reprod Contracept Obstet Gynecol 2021;10:2950-4. 